\title{
Interioridad y trascendencia. Asimilación de la interioridad agustiniana en el pensamiento cusano: hacia la subjetividad moderna
}

\author{
Alexia Schmitt (2017). \\ Buenos Aires: Biblos. \\ ISBN 978-987-691-471-0, 314 pp.
}

\section{( Cristina López}

Universidad Nacional de San Martín

Interioridad y Trascendencia es un texto surgido de una minuciosa investigación en vista de la obtención del Doctorado en Filosofía; es la cuarta tesis sobre el Cusano convertida en libro y editada en la colección Presencias Medievales.

Especialista en Filosofía Medieval, particularmente en la obra de Nicolás de Cusa, Alexia Schmitt ha elegido un doble y complejo enfoque para ahondar en la exploración del pensamiento del Cusano puesto que, en principio, ha indagado las vías de recepción de la concepción de la interioridad agustiniana y su incidencia en la conformación de la concepción cusana y, en segundo lugar, ha intentado llevar luz al debate acerca del grado de influencia que esta ha tenido sobre la concepción moderna de la subjetividad.

A primera vista podría sospecharse que, lejos de facilitar el acceso al pensamiento de Nicolás de Cusa, este enfoque habilita un desplazamiento de la mirada, por un lado, hacia sus antecedentes y, por el otro, hacia sus incidencias. No obstante, contra toda apariencia, en modo alguno estas claves de lectura implican un desvío del análisis del pensamiento del autor. Por el contrario, desde ambos puntos de vista, la investigación constituye un aporte a los estudios de la obra cusana. Ello es mérito de la autora, quien no se obnubila por las similitudes que podrían diluir la especificidad de la concepción de la interioridad cusana en beneficio de su asimilación al planteo de Agustín o al de la modernidad y opta por llevar adelante una tarea mucho más esforza$\mathrm{da}$, consistente en detectar los matices diferenciadores que permiten captar la peculiaridad del planteo del Cusano.

De hecho, en cuanto al primer enfoque, Schmitt ha procurado mostrar que, si bien la interioridad agustiniana constituye el fundamento de la cusana, esta última significa una verdadera superación respecto de la matriz de la cual parte. Para ello, se ha tomado el trabajo de reconstruir el camino por el cual Nicolás de Cusa pudo ponerse en contacto con la obra de Agustín. No se trata de un trabajo menor por cuanto, además del rastreo de los testimonios que constatan el conocimiento directo que el Cusano tenía de la obra agustiniana y, en particular, de su concepción de interioridad, conlleva el estudio profundo del pensamiento de ambos autores.

Fruto de ese estudio, la autora advierte tanto la recepción de la noción agustiniana en la gnoseología cusana como el aporte de este último. En efecto, sin dejar de reconocer que “... el concepto agustiniano de interioridad con su capacidad de volver sobre sí y trascenderse nocionalmente, constituye el presupuesto por el cual la mens es capaz de ingresar al camino de la docta ignorancia...."(p. 165) Schmitt sostiene que, mientras que en Agustín ratio e intellectus coinciden, en el Cusano representan dos modalidades distintas de conocer, a saber, una que sirviéndose de la razón distingue las oposiciones y respeta el principio de no contradicción, otra que valiéndose del intelecto trasciende las aparentes contradicciones y permite entrever que todo proviene y tiende hacia el principio. No es esta la única diferencia gnoseológica entre ambos filósofos que detecta nuestra autora, quien supo distinguir que allí donde Agustín fundaba en la condición pecadora del hombre su imposibilidad de acceder a la comprensión de Dios, el Cusano recurrió a una explicación más filosófica, consistente en mostrar que el conocer limitado del hombre no puede abarcar la infinitud del principio.

Con igual agudeza, Schmitt detecta, aún en planteos coincidentes, una serie de matices que permiten percibir el aporte del Cusano. Así señala que, compartiendo la idea de que la finalidad de todo conocimiento humano consiste en aproximarse al principio unitrino, en su obra, el Cusano subraya enfáticamente que el verdadero conocimiento conduce a la unidad originaria y destaca el carácter conjetural del saber de Dios alcanzado tanto por la vía de la contemplación del mundo como por la interiorización en nuestra mens. Del mismo modo, aunque incorpora la fórmula de la mens humana 
como imago Dei, el Cusano le añade el adjetivo "viviente" para acentuar el carácter dinámico del proceso a través del cual el hombre se va asimilando a Dios. Un matiz mayor entre ambos autores se expresa en la fórmula "Sé tú tuyo y yo seré tuyo" que Nicolás interpone para referir el camino para alcanzar la posesión de Dios diferenciándose de tal suerte de Agustín para quien es menester trascender nuestro ser finito para acercarnos al principio divino.

Con idéntica sutileza, la autora enfoca el análisis del aporte del modelo de interioridad cusana a la concepción moderna de subjetividad. Efectivamente, reconociendo los cuatro rasgos propios de la interioridad cusana que, a primera vista, parecen preparar el camino de la subjetividad moderna, a saber, la unidad de quien conoce, lo conocido y el acto mismo del conocer en la mens humana, el carácter creativo del conocer humano, la admisión del perspectivismo y la ponderación del ser del hombre, nuestra autora no deja de ponderar las diferencias que distancian la concepción de Nicolás de la moderna. Así, en lugar de plegarse a los intérpretes que, siguiendo a Cassirer, consideran el perspectivismo cusano como un anticipo del moderno o reducir, como hacen otros especialistas, la metafísica cusana al rango de mera continuadora de las doctrinas neoplatónicas, Alexia Schmitt opta por asumir una posición intermedia consistente, por una parte, en diferenciarse de los "pro-modernos" destacando la importancia que Nicolás le adjudica a la singularidad y subjetividad pero sin olvidar el carácter dependiente y mediador que les adjudica y, por otra parte, diferenciándose de los proneoplatónicos, dando cuenta de la constitución trascendental en sentido intelectual, sensible y ético de la subjetividad cusana.

Por último, es necesario poner de relieve el Apéndice en el cual se editan las marginales cusanas al Codex Cusanus 34, es decir, el manuscrito de la Biblioteca de Kues que contiene una versión de Confessiones anotada por el Cusano. Se trata de la única edición de esas notas lo cual vuelve al libro de Alexia Schmitt una herramienta indispensable para el especialista del pensamiento cusano en general y el estudioso de sus fuentes en particular. 